\title{
Easy to Swallow Rice Cake as a Carbohydrate Source during Endurance Exercise Suppressed Feelings of Thirst and Hunger without Changing Exercise Performance
}

\author{
Kengo ISHIHARA $^{1}$, Hirokazu TANIGUCHI ${ }^{2}$, Nao AKIYAMA ${ }^{1}$ and Yuya AsAmI ${ }^{1}$ \\ ${ }^{1}$ Department of Food Science and Human Nutrition, Faculty of Agriculture, Ryukoku University, \\ Shiga 520-2194, Japan \\ ${ }^{2}$ Division of Applied Life Sciences, Graduate School of Life and Environmental Sciences, \\ Kyoto Prefectural University, Kyoto 606-8522, Japan
}

(Received June 5, 2019)

\begin{abstract}
Summary The present guidelines for sports nutrition recommend relatively higher doses of carbohydrates (CHO) for endurance exercise. There is a need for novel food products that are solid but easy to swallow and supply a large dose of $\mathrm{CHO}$ without gastrointestinal distress (ingesting a large amount of sugar solution may cause gastrointestinal distress because of its high osmolality). We prepared a modified rice cake (SPRC, sweet potato rice cake) and assessed its properties in swallowing and mastication; we also assessed the availability of this modified rice cake as a $\mathrm{CHO}$ source during endurance exercise. The number of chewing strokes with the SPRC tended to be lower compared to glutinous rice cakes. The exercise protocol consisted of $1 \mathrm{~h}$ at $80 \% \mathrm{VO}_{2 \max }$ plus a continuous time trial. The subjects were administered a commercially available jelly drink (CHO gel) or SPRC at 0 and 30 min during exercise and immediately after completing the time trial. Heart rate, oxygen consumption, blood glucose elevation, and the rate of perceived exertion did not differ among the trials during exercise. However, the visual analog scale rating revealed that SPRC significantly suppressed hunger and sweetness ratings $(p<0.05)$ and tended to suppress thirst ratings $(p<0.10)$ during exercise. The palatability rating did not differ between the SPRC and CHO gel during exercise at $80 \% \mathrm{VO}_{2 \max }$ and immediately after the time trial. In conclusion, preand during exercise ingestion of the SPRC suppressed sweetness, thirst, and hungry ratings without interfering with exercise performance.
\end{abstract}

Key Words glycemic index, gastrointestinal distress, blood glucose, ergogenic aids, carbohydrate

The ingestion of carbohydrate ( $\mathrm{CHO})$ during exercise has several effects on metabolism and can provide multiple performance benefits (1). Current $\mathrm{CHO}$ intake recommendations suggest that athletes consume 30-60 g/h of CHO during 75-180 min of exercise and $90 \mathrm{~g} / \mathrm{h}$ of $\mathrm{CHO}$ during $>150 \mathrm{~min}$ of exercise (2). There are approximately $5 \mathrm{~g} / 100 \mathrm{~mL}$ of $\mathrm{CHO}$ in common sports drinks; therefore, fluid intake must reach $600-1,200 \mathrm{~mL} / \mathrm{h}$ to supply enough $\mathrm{CHO}$ from common sports drinks.

Hyperosmolar solutions increase gastrointestinal problems (3). Thus, endurance athletes, such as cyclists and triathletes, regularly consume solid forms of $\mathrm{CHO}$ (e.g., energy bars) in addition to liquids (e.g., sports drink) or gels (e.g., CHO gel). Solid food has a higher content of $\mathrm{CHO}$ compared to drinks or gels. However, a disadvantage of solid food is the extra effort of mastication and swallowing. Therefore, semi-solid food, which has intermediate properties between gels and solids, would be appropriate as a CHO supply during endurance exercise because it can alleviate the extra effort of mastication and swallowing.

Glutinous rice cake is a traditional Asian food made from kneaded glutinous rice. Glutinous rice cake has the following characteristics that make it suitable as a $\mathrm{CHO}$ source during endurance exercise: first, glutinous rice cake is made from starch and has one of the highest CHO contents of major foods (4). Second, glutinous rice cake is good for digestion and has a higher glycemic index than bread (5). However, glutinous rice cake is not used for $\mathrm{CHO}$ supplementation during endurance exercise because it generally requires the additional effort of chewing and swallowing compared to liquids (6).

Therefore, glutinous rice cake can be used as a $\mathrm{CHO}$ source during endurance exercise if its difficulties in mastication and swallowing are improved. In the present study, we modified the physical properties of glutinous rice cake by adding sweet potato to reduce the effort of mastication and swallowing. Sweet potato starches are suitable for foodstuffs because of their low pasting temperature and slow retrogradation; moreover, sweet potato is essentially gluten-free (7). Furthermore, we compared the characteristics of the modified rice cake with $\mathrm{CHO}$ gels to assess its application as a CHO supply source during endurance exercise in trained cyclists. 
Table 1. Nutritional composition of carbohydrate sources in experiments 1 and 2 .

\begin{tabular}{lrcc}
\hline & CHO gel & SPRC & Glutinous rice cake \\
\hline Weight $(\mathrm{g})$ & 80 & 50 & 35 \\
Energy (kcal) & 80 & 80 & 80 \\
Carbohydrate $(\mathrm{g})$ & 20 & 18.5 & 18 \\
Protein $(\mathrm{g})$ & 0 & 0.9 & 1.5 \\
Fat $(\mathrm{g})$ & 0 & 0.1 & 0.2 \\
Water $(\mathrm{g})$ & 60 & 31 & 15 \\
\hline
\end{tabular}

Values are nutritional contents for $80 \mathrm{kcal}$ of diet.

\section{MATERIALS AND METHODS}

Materials. Water, CHO gel (Weider in Jelly, Morinaga \& Co., Ltd., Tokyo, Japan), glutinous rice cake (Kirimochi $^{\mathrm{TM}}$, Sato Food Co., Ltd., Niigata, Japan), and sweet potato rice cake (SPRC) were used for the masticatory electromyography (EMG) measurements (experiment 1). The CHO gel and SPRC were also used for the exercise study (experiment 2). The nutritional values of each sample were calculated based on Standard Tables of Food Composition in Japan (4); these values are shown in Table 1. All procedures were approved by the Ryukoku University Human Research Ethics Review Board (No. 2016-08-02). All research procedures complied with the code of ethics of the World Medical Association (Declaration of Helsinki) and all procedures with the Helsinki Declaration of 1975, as revised in 2000.

SPRC was prepared from glutinous rice powder (Shiratamako, Kyouyamashiroya, Co., Ltd., Kyoto, Japan), sweet potato (Naruto Kintoki, Fresco, Co., Ltd., Kyoto, Japan), sucrose (White Sugar, Mitsui Sugar Co., Ltd., Tokyo, Japan), and water. Briefly, $100 \mathrm{~g}$ of glutinous rice powder, $20 \mathrm{~g}$ of sucrose, and $150 \mathrm{~g}$ of water were mixed well until it became a uniform white solution. Separately, $200 \mathrm{~g}$ of sweet potato was steamed for $20 \mathrm{~min}$ at $100^{\circ} \mathrm{C}$ in a steam convection oven (model FSCCWE101, Fujimac Co., Ltd., Tokyo, Japan) and mashed well. The white solution was poured into the mashed sweet potato, and these components were mixed to obtain a light yellow creamy solution. Fifty grams of the solution was poured into a transparent plastic bag $(0.1 \mathrm{~mm}$ thick, $75 \mathrm{~mm}$ wide, and $130 \mathrm{~mm}$ long, Taiyousha Co., Ltd., Osaka, Japan) and sealed under reduced pressure using a vacuum cooker (model V-380G, TOSEI Co., Ltd., Tokyo, Japan). The vacuum product was steamed for $10 \mathrm{~min}$ at $100^{\circ} \mathrm{C}$ in the steam convection oven. The SPRC was then stored at $-20^{\circ} \mathrm{C}$.

Exp. 1. Masticatory EMG study. All the samples, except for water, contained $20 \mathrm{kcal}$ of energy; the water, $\mathrm{CHO}$ gel, SPRC, and glutinous rice cake each weighed $20,20,12$, and $9 \mathrm{~g}$, respectively. The glutinous rice cake was cooked for $75 \mathrm{~s}$ in boiling water and then cooled in a covered plastic Petri dish for $10 \mathrm{~min}$ at room temperature $\left(25^{\circ} \mathrm{C}\right)$. The SPRC was removed from the freezer and thawed for $30 \mathrm{~min}$ at room temperature $\left(25^{\circ} \mathrm{C}\right)$.

Five volunteers $($ age $=29.8 \pm 9.8 y)$, who were free from functional mastication problems and required no dental treatment, participated in the mastication and swallowing measurements. Two replicates of each sample were randomly served to the subjects. Each volunteer consumed water and CHO gel by cup, SPRC and glutinous rice cake by chopsticks in a random order.

The EMG activities from the right masseter muscles and the suprahyoid musculature were recorded with tripolar surface electrodes and an amplifier (Mwatch, Wada seisakujo Co., Aichi, Japan). The signal from these masseter muscle EMGs was used to derive i) the number of chewing strokes, ii) mastication time, and iii) mean chewing cycle time. Based on the signal from the suprahyoid muscle EMGs, iv) swallowing time was derived. For each EMG, v) the maximum voltage and vi) muscle activity estimated as the time-integral of the EMG voltages were determined (8).

Exp. 2. Exercise study.

Subjects: Six trained male cyclists $[$ age $=24.5 \pm 9.6 \mathrm{y}$, height $=1.72 \pm 0.04 \mathrm{~m}$, body weight $=59.8 \pm 3.8 \mathrm{~kg}$, $\mathrm{VO}_{2 \max }=62.1 \pm 7.2 \mathrm{~mL} \cdot \mathrm{kg}^{-1} \cdot \mathrm{min}^{-1}$, and peak power $\left.\left(W_{\max }=333.4 \pm 32.6 \mathrm{~W}\right)\right]$ participated in this study. All subjects had $\geq 2$ y cycling experience and had cycled $\geq 2 \mathrm{~d} \cdot \mathrm{wk}^{-1}$ and $\geq 6 \mathrm{~h} \cdot \mathrm{wk}^{-1}$ for the preceding two months while regularly competing in races. Prior to giving their oral and written informed consent, all subjects received information regarding the requirements of the study and potential risks.

Study design: This was a randomized crossover study that consisted of baseline testing to determine $\mathrm{VO}_{2 \max }$ and $W_{\max }$, a familiarization trial, and two experimental trials. Each experimental trial was separated by $7 \mathrm{~d}$. The subjects were asked to maintain consistent dietary and training habits throughout the study period. Prior to each experimental trial, exercise, and diet were standardized. The subjects were asked to refrain from exercise on the day prior to the first experimental trial. Additionally, the subjects were asked to replicate their diet the day prior to each experimental trial. The subjects were also asked to abstain from alcohol and caffeine for the $24 \mathrm{~h}$ preceding each experimental trial.

Baseline testing and familiarization: During the initial visit to the laboratory, the subjects were assessed for $\mathrm{VO}_{2 \max }$ and $\mathrm{W}_{\max }$ and acclimated to the exercise load. This consisted of a continuous graded exercise test to exhaustion on a cycle ergometer (Combi 75XL III, Konami Holdings Co., Ltd., Tokyo, Japan). Commencing with a warm-up at $50 \mathrm{~W}$, power was increased by ramp protocol (15 W every minute) until volitional exhaustion. $\mathrm{VO}_{2 \max }$ was assessed with a calibrated metabolic cart (AE-310S, Minato Medical Science Co., Ltd., Osaka, Japan) and was classified as the highest average 15-s oxygen consumption $\left(\mathrm{mL} \cdot \mathrm{kg}^{-1} \cdot \mathrm{min}^{-1}\right)$ recorded. $W_{\text {max }}$ was the wattage attained in the last completed stage plus the fraction completed of the stage at which exhaustion occurred. An acclimation trial was completed $30 \mathrm{~min}$ after assessing $\mathrm{VO}_{2 \max }$ and $\mathrm{W}_{\text {max }}$. The familiarization trial consisted of the $15 \mathrm{~min}$ of $80 \% \mathrm{VO}_{2 \max }$ followed by a time trial to achieve the consumption of $383 \mathrm{~kJ}$ of energy expenditure. 
Experimental trials: Subjects reported to the laboratory at $1300-1400 \mathrm{~h}$ following $3 \mathrm{~h}$ of fasting. The arrival times were replicated for subsequent trials. Following $5 \mathrm{~min}$ of rest in the seated position on the bicycle ergometer, resting heart rate (Polar ${ }^{\circledR}$ RS800CX, Polar, Inc., Kempele, Finland) was assessed, and a 5-min indirect calorimetry measurement was taken with the final 3 min being used in the subsequent analysis. A finger prick blood sample was collected for the immediate measurement of blood glucose (OneTouch Ultraview, Johnson \& Johnson Co., Ltd., NJ) and lactate (Lactate Pro 2, Arklay, Co., Ltd., Kyoto, Japan) during the 5-min resting period. Blood, heart rate, and indirect calorimetry measurements were repeated at 30 and 60 min during exercise. Next, the subjects received a pre-exercise treatment diet, which they consumed within $1 \mathrm{~min}$, and began to exercise. The subjects commenced exercise with a 5min warm-up at $30 \% \mathrm{VO}_{2 \max }$. The exercise protocol is presented in Fig. 1. The protocol consisted of a 5-min warm-up and $55 \mathrm{~min}$ at $80 \% \mathrm{VO}_{2 \max }$ followed by a time trial to achieve the consumption of $383 \mathrm{~kJ}$ of energy expenditure. Before the time trial, the subjects recovered by spinning freely at a light workload $(<30 \mathrm{~W})$ for $2 \mathrm{~min}$. The total exercise time was $67^{\prime} 51^{\prime \prime} \pm 0^{\prime} 34^{\prime \prime}$ and $67^{\prime} 42^{\prime \prime} \pm 0^{\prime} 36^{\prime \prime}$ in the SPRC and CHO gel groups,

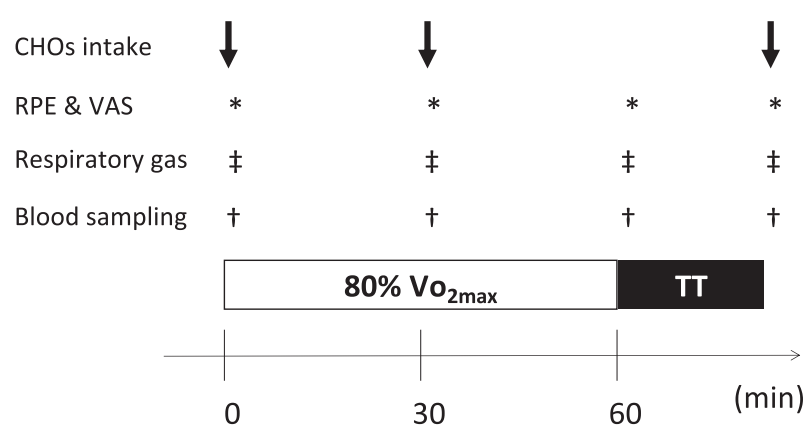

Fig. 1. Schematic design of the exercise study (experiment 2). RPE, rate of perceived exertion; VAS, visual analog scale for the survey of subjective parameters; TT, time trial. ${ }^{\dagger} p<0.05$ vs 0 min. respectively.

The heart rate, blood glucose, blood lactate, and rate of perceived exertion were measured every 30 min during the $60 \mathrm{~min}$ exercise and immediately after the time trial. Indirect calorimetry measurements were assessed every 30 min during the 60 min exercise.

All testing was completed in thermoneutral conditions $\left(22^{\circ} \mathrm{C}, 45-50 \%\right.$ humidity). The subjects were cooled by a pedestal fan on the medium setting in each trial for uniform cooling. During the performance testing portion of the exercise protocol, the subjects received no verbal encouragement and were only permitted to see the amount of work completed.

Experimental diets: The exercise study evaluated the originally developed SPRC and a commercially available CHO gel. The following treatments were assessed: each subject consumed $80 \mathrm{kcal}$ of SPRC or $\mathrm{CHO}$ gel at the start of the exercise, at 30 and 60 min during exercise, and immediately after the time trial. Each diet contained 18.5 and $20 \mathrm{~g}$ of $\mathrm{CHO}$, respectively as shown in Table 1. Therefore, 37 and $40 \mathrm{~g}$ of $\mathrm{CHO}$ were consumed from the SPRC and $\mathrm{CHO}$ gel during $60 \mathrm{~min}$ of exercise, respectively.

Perceptual response assessment: The perceptual response to the taste of the samples and associated feelings related to sweetness, palatability, thirst, fullness, and hunger were assessed via a 100-mm visual analog scale, as previously described (9). Perceptual responses were assessed every $30 \mathrm{~min}$ during the first $60 \mathrm{~min}$ of exercise and immediately after the time trial.

Calculations: Total $\mathrm{CHO}$ and fat oxidation at rest and during the first 60 min of exercise were calculated from indirect calorimetry measurements based on Frayn's equation (10).

Statistics. Data are presented as the means and standard deviations. To statistically analyze the mastication parameters in experiment 1 , a one-way ANOVA was used; comparisons between samples were performed by Tukey's post hoc test. To statistically analyze the metabolic parameters and perceptual response in experiment 2, twoway repeated measure of ANOVA followed by Sidak's

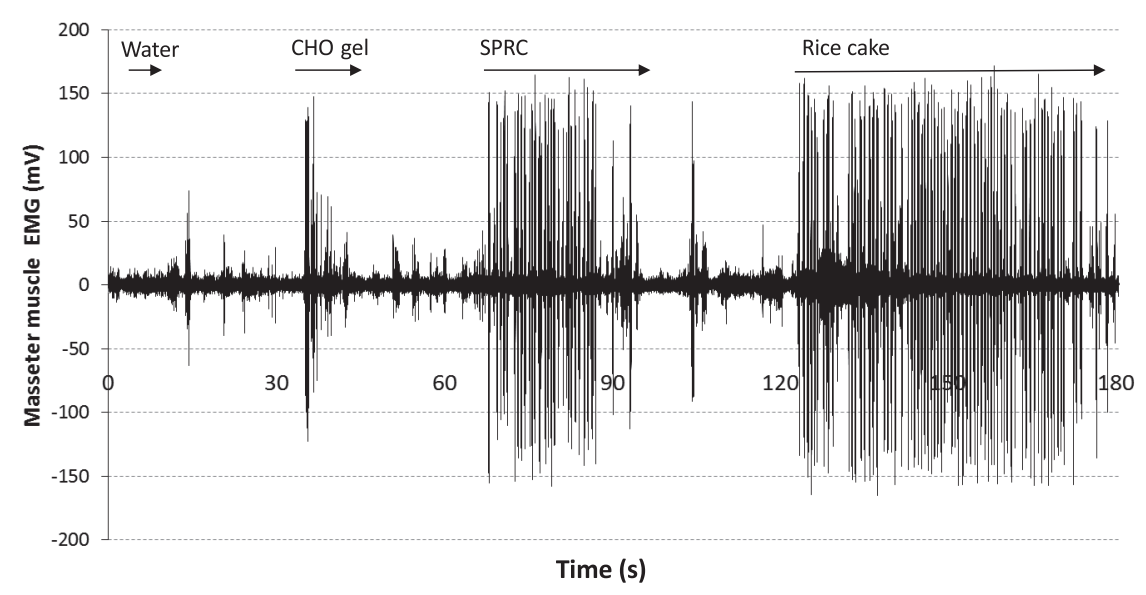

Fig. 2. Typical EMG signals during the mastication of water, $\mathrm{CHO}$ gel, SPRC, and glutinous rice cake. Each sample was $20 \mathrm{kcal}$, except for water, and their weights were 20, 12, 9, and $5 \mathrm{~g}$ for water, CHO gel, SPRC, and glutinous rice cake, respectively. 
Table 2. Mastication and swallowing parameters.

\begin{tabular}{|c|c|c|c|c|}
\hline & Water & $\mathrm{CHO}$ gel & SPRC & Glutinous rice cake \\
\hline \multicolumn{5}{|l|}{ Mastication parameters } \\
\hline \multicolumn{5}{|l|}{ Number of chewing } \\
\hline Strokes & $0.0 \pm 0.0^{\mathrm{a}}$ & $6.2 \pm 9.4^{\mathrm{a}}$ & $16.8 \pm 8.7^{\mathrm{ab}}$ & $35.6 \pm 22.6^{b}$ \\
\hline Mastication time (s) & $0.0 \pm 0.0^{\mathrm{a}}$ & $11.6 \pm 8.7^{\mathrm{ab}}$ & $13.2 \pm 7.2^{\mathrm{ab}}$ & $26.4 \pm 17.6^{\mathrm{b}}$ \\
\hline Chewing cycle (s) & $0.0 \pm 0.0^{\mathrm{a}}$ & $3.9 \pm 3.9^{b}$ & $0.8 \pm 0.1^{\mathrm{a}}$ & $0.8 \pm 0.1^{\mathrm{a}}$ \\
\hline \multicolumn{5}{|l|}{ Masseter muscles } \\
\hline Amplitude $(\mu \mathrm{V})$ & $108.1 \pm 48.1^{\mathrm{a}}$ & $200.4 \pm 45.1^{\mathrm{b}}$ & $318.9 \pm 11.1^{\mathrm{c}}$ & $342.3 \pm 12.0^{\mathrm{c}}$ \\
\hline Total muscle activity $(\mu \mathrm{V} \cdot \mathrm{s})$ & $137.4 \pm 116.0^{\mathrm{a}}$ & $102.1 \pm 12.8^{\mathrm{a}}$ & $255.6 \pm 76.8^{\mathrm{b}}$ & $501.6 \pm 155.0^{\mathrm{b}}$ \\
\hline \multicolumn{5}{|l|}{ Swallowing parameters } \\
\hline Swallowing time (s) & $3.0 \pm 1.2^{\mathrm{a}}$ & $13.4 \pm 5.8^{\mathrm{ab}}$ & $17.8 \pm 7.1^{\mathrm{ab}}$ & $28.8 \pm 22.2^{\mathrm{b}}$ \\
\hline \multicolumn{5}{|l|}{ Suprahyoid muscles } \\
\hline Amplitude $(\mu \mathrm{V})$ & $258.6 \pm 20.6^{\mathrm{a}}$ & $283.5 \pm 36.5^{\mathrm{ab}}$ & $300.6 \pm 34.0^{\mathrm{ab}}$ & $315.5 \pm 15.5^{b}$ \\
\hline Total muscle activity $(\mu \mathrm{V} \cdot \mathrm{s})$ & $208.1 \pm 64.4^{\mathrm{a}}$ & $352.6 \pm 105.0^{\mathrm{ab}}$ & $521.7 \pm 232.0^{\mathrm{ab}}$ & $660.4 \pm 289.3^{\mathrm{b}}$ \\
\hline
\end{tabular}

Values not sharing common superscrips are significantly different, $p<0.05$. Values are means \pm SD $(n=5)$.

multiple comparisons test was performed using statistical software (Prism ver. 7.0, GraphPad Software). Statistical significance was set at $p<0.05$.

\section{RESULTS}

\section{Mastication parameters}

We compared the mastication difficulties of SPRC with glutinous rice cake and $\mathrm{CHO}$ gel by electromyography (Fig. 2). SPRC can be squeezed by grasping the plastic bag (Supplemental Online Material (video)). The mean number of chewing strokes of SPRC (16.8 $\pm 8.7 \mathrm{~s})$ was between that of $\mathrm{CHO}$ gel $(6.2 \pm 9.4 \mathrm{~s})$ and glutinous rice cake $(35.6 \pm 22.6 \mathrm{~s})$. The mean mastification time of SPRC (13.2 $\pm 7.2 \mathrm{~s})$ was also between that of $\mathrm{CHO}$ gel $(11.6 \pm 8.7 \mathrm{~s})$ and glutinous rice cake $(26.4 \pm 17.6 \mathrm{~s})$. The total masseter muscles activity in the SPRC (255.6士 $76.8 \mu \mathrm{V} \cdot \mathrm{s}$ ) was $49.0 \%$ lower compared to glutinous rice cake $(501.6 \pm 155.0 \mu \mathrm{V} \cdot \mathrm{s})$. Furthermore, the mean swallowing time for the SPRC and $\mathrm{CHO}$ gel was 11.0 and $15.4 \mathrm{~s}$ shorter than the glutinous rice cake, respectively. The total muscle activity of the suprahyoid muscles in the SPRC $(521.7 \pm 232 \mu \mathrm{V} \cdot \mathrm{s})$ was $21.1 \%$ lower than that of the glutinous rice cake $(660.4 \pm 289.3 \mu \mathrm{V} \cdot \mathrm{s}$, Table 2).

Biochemical analysis

Biological analysis and respiratory parameters were shown in Table 3. The blood glucose concentration significantly increased above resting levels following the start of exercise in both trials when either SPRC or CHO gel was administered (main effect, $F=4.47, p<0.05$ ). The blood glucose concentration was maintained until $60 \mathrm{~min}$ of exercise at an exercise intensity of $80 \%$ $\mathrm{VO}_{2 \max }$. There was no main effect of diet on blood glucose concentration (main effect, $F=0.13, p=0.73$ ) with no interaction effects (interaction, $F=0.64, p=0.59$ ).

Plasma lactate concentrations were significantly elevated at the end of all time trials (main effect, $F=50.6$, $p<0.001)$ compared to values measured after $60 \mathrm{~min}$ of cycling exercise. There were no main effects of diet (main effect, $F=1.03, p=0.35$ ) with no interaction effects (interaction, $F=0.68, p=0.57)$.
Table 3. Physiological performance parameters during exercise.

\begin{tabular}{|c|c|c|c|}
\hline & & $\mathrm{CHO}$ gel & SPRC \\
\hline $\begin{array}{l}\text { Blood glucose } \\
(\mathrm{mg} / \mathrm{dL})\end{array}$ & $\begin{array}{l}0 \mathrm{~min} \\
30 \mathrm{~min} \\
60 \mathrm{~min} \\
\text { Post TT }\end{array}$ & $\begin{array}{c}88.2 \pm 9.5^{\mathrm{a}} \\
98.2 \pm 11.8^{\mathrm{a}} \\
97.5 \pm 6.9^{\mathrm{a}} \\
118.7 \pm 38.8^{\mathrm{b}}\end{array}$ & $\begin{array}{r}93.2 \pm 10.5^{\mathrm{a}} \\
102.3 \pm 12.3^{\mathrm{a}} \\
105.7 \pm 12.4^{\mathrm{a}} \\
110.2 \pm 20.2^{\mathrm{b}}\end{array}$ \\
\hline $\begin{array}{l}\text { Blood lactate } \\
(\mathrm{mM})\end{array}$ & $\begin{array}{l}0 \mathrm{~min} \\
30 \mathrm{~min} \\
60 \mathrm{~min} \\
\text { Post TT }\end{array}$ & $\begin{array}{r}1.7 \pm 1.0^{\mathrm{a}} \\
3.2 \pm 1.0^{\mathrm{a}} \\
3.2 \pm 1.4^{\mathrm{a}} \\
12.6 \pm 4.0^{\mathrm{b}}\end{array}$ & $\begin{array}{r}2.2 \pm 0.9^{\mathrm{a}} \\
4.5 \pm 1.0^{\mathrm{a}} \\
3.0 \pm 0.3^{\mathrm{a}} \\
12.7 \pm 3.1^{\mathrm{b}}\end{array}$ \\
\hline $\begin{array}{l}\text { Respiratory } \\
\text { exchange ratio }\end{array}$ & $\begin{array}{l}0 \mathrm{~min} \\
30 \mathrm{~min} \\
60 \mathrm{~min}\end{array}$ & $\begin{array}{l}0.84 \pm 0.1 \\
0.86 \pm 0.1 \\
0.87 \pm 0.1\end{array}$ & $\begin{array}{l}0.84 \pm 0.1 \\
0.86 \pm 0.0 \\
0.87 \pm 0.0\end{array}$ \\
\hline $\begin{array}{l}\mathrm{VO}_{2} \\
(\mathrm{~mL} / \mathrm{min} / \mathrm{kg})\end{array}$ & $\begin{array}{l}0 \mathrm{~min} \\
30 \mathrm{~min} \\
60 \mathrm{~min}\end{array}$ & $\begin{array}{r}7.8 \pm 2.8^{\mathrm{a}} \\
51.6 \pm 5.5^{\mathrm{b}} \\
52.9 \pm 5.6^{\mathrm{b}}\end{array}$ & $\begin{array}{r}6.0 \pm 1.4^{\mathrm{a}} \\
50.0 \pm 6.1^{\mathrm{b}} \\
50.0 \pm 8.6^{\mathrm{b}}\end{array}$ \\
\hline $\begin{array}{l}\text { Heart rate } \\
(\mathrm{bpm})\end{array}$ & $\begin{array}{l}0 \mathrm{~min} \\
30 \mathrm{~min} \\
60 \mathrm{~min} \\
\text { Post TT }\end{array}$ & $\begin{array}{c}81.8 \pm 10.0^{\mathrm{a}} \\
149.7 \pm 7.6^{\mathrm{b}} \\
149.7 \pm 8.0^{\mathrm{b}} \\
176.0 \pm 6.9^{\mathrm{c}}\end{array}$ & $\begin{array}{c}73.7 \pm 4.8^{\mathrm{a}} \\
155.2 \pm 6.0^{\mathrm{b}} \\
161.0 \pm 6.7^{\mathrm{b}, \dagger} \\
183.0 \pm 10.4^{\mathrm{c}}\end{array}$ \\
\hline $\begin{array}{l}\text { Rate of } \\
\text { perceived } \\
\text { exertion }\end{array}$ & $\begin{array}{l}0 \mathrm{~min} \\
30 \mathrm{~min} \\
60 \mathrm{~min} \\
\text { Post TT }\end{array}$ & $\begin{array}{r}6.0 \pm 0.0^{\mathrm{a}} \\
12.7 \pm 0.5^{\mathrm{b}} \\
14.0 \pm 2.1^{\mathrm{b}} \\
18.2 \pm 1.5^{\mathrm{c}}\end{array}$ & $\begin{array}{r}6.0 \pm 0.0^{\mathrm{a}} \\
13.2 \pm 0.8^{\mathrm{b}} \\
13.5 \pm 0.8^{\mathrm{b}} \\
18.0 \pm 1.5^{\mathrm{c}}\end{array}$ \\
\hline
\end{tabular}

Values are means \pm SD $(n=6)$. Values without common superscript between time points in the same diet are significantly different, $p<0.05 .{ }^{\dagger} p<0.10$ vs $\mathrm{CHO}$ gel at the same exercise time.

Respiratory parameters, heart rate, and rate of perceived exertion (RPE)

Oxygen consumption was significantly elevated after the start of exercise in SPRC and CHO gel group (main effect, $F=268.5, p<0.001$ ). Oxygen consump- 

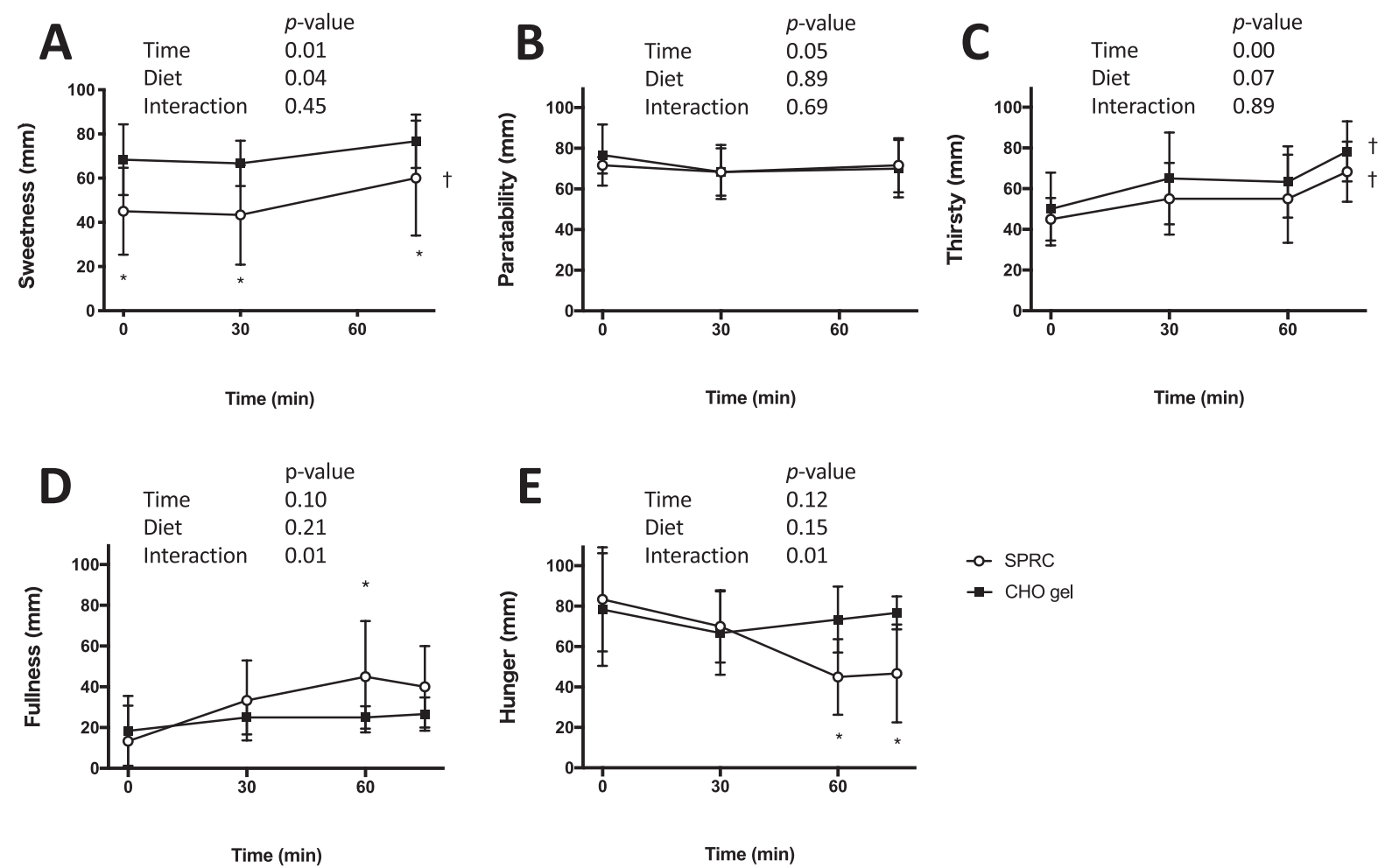

Fig. 3. Subjective feelings during $60 \mathrm{~min}$ of exercise. The visual analog scale (VAS) was used to measure sweetness (A), ease of mastication and swallowing (palatability, B), thirst (C), fullness (D) and hunger (E). Values are the means \pm SD $(n=6) .{ }^{\dagger} p<0.05$ vs $0 \mathrm{~min},{ }^{*} p<0.05$ vs $\mathrm{CHO}$ gel.

tion tended to be lower in SPRC (main effect, $F=4.74$, $p=0.08$ ), with no interaction effects (interaction, $F=$ $0.20, p=0.81)$. The respiratory exchange ratio did not change throughout the $60 \mathrm{~min}$ of cycling exercise (all main effects and interaction, $F<1.19, p=0.34$ ).

Heart rates were significantly elevated at 30 and 60 min of cycling exercise compared to the value measured at the start of exercise (main effect, $F=885.1$, $p<0.001)$. The heart rate tended to be higher in the SPRC group than in the $\mathrm{CHO}$ gel group 60 min after the start of exercise with interaction effects in heart rate. Further increase of heart rates were observed during the time trial compared to the value measured at $60 \mathrm{~min}$ of exercise (interaction, $F=9.16, p<0.01$ ).

There was an incremental increase in the average RPE values in both groups after 30 and 60 min of cycling exercise compared to the resting period (main effect, $F=198.8, p<0.001)$. There were no main effects of diet (main effect, $F=0.01, p=0.80$ ), with no interaction effects in RPE (interaction, $F=0.55, p=0.65$ ).

Sweetness, palatability, thirsty, fullness, and hunger

The sweetness rating was significantly lower in the SPRC group compared to the $\mathrm{CHO}$ gel group all time during exercise (main effect, $F=7.46, p<0.05$ ). There were main effects of time (main effect, $F=6.33, p<$ 0.05 ), with no interaction effects (interaction, $F=0.87$, $p=0.45$ ) in sweetness rating (Fig. $3 \mathrm{~A}$ ). The palatability rating, which is the ease of mastication and swallowing, did not differ between the subjects receiving SPRC and CHO gel all time during exercise (main effect, $F=0.02$, $p=0.89$ ). There were no main effects of time (main

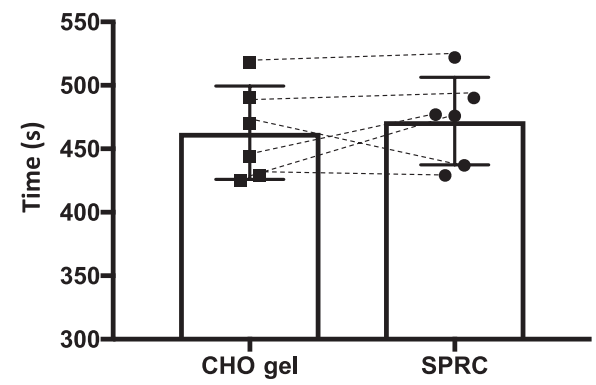

Fig. 4. Time trial score after $60 \mathrm{~min}$ of exercise at $80 \%$ $\mathrm{VO}_{2 \text { max }}$. Values are the means $\pm \mathrm{SD}(n=6)$.

effect, $F=3.94, p=0.05$ ), with no interaction effects (interaction, $F=0.39, p=0.69$ ) in the palatability rating (Fig. 3B). The thirst rating tended to be lower in the SPRC group (main effect, $F=5.26, p=0.07$ ). There were main effects of time (main effect, $F=11.42, p<0.001$ ) with no interaction effects (interaction, $F=0.20, p=$ 0.89 ) in the thirst rating (Fig. 3C). The fullness rating was significantly higher in the SPRC group compared to the $\mathrm{CHO}$ gel group during $60 \mathrm{~min}$ of exercise (interaction, $F=7.24, p<0.05)$. There were no main effects of diet and time (main effects, $F=1.98$ and 2.39, $p=0.21$ and 0.11 for sample and time, respectively) in fullness rating (Fig. 3D). Similarly, the hunger rating was significantly lower in the SPRC group compared to the CHO gel group during $60 \mathrm{~min}$ of exercise (interaction, $F=7.24, p<0.01)$. There were no main effects of diet and time (main effects, $F=2.86$ and 2.22, $p=0.15$ and 
0.12 for sample and time, respectively) in hunger rating (Fig. 3E).

\section{Time trial performance}

There were no differences in time and average power (7'42" $\pm 0^{\prime} 36^{\prime \prime}$ vs. $7^{\prime} 51^{\prime \prime} \pm 0^{\prime} 34^{\prime \prime}$ in the SPRC and CHO gel groups, respectively) between the two groups during the time trial (Fig. 4).

\section{DISCUSSION}

Glutinous rice cake contains high amounts of $\mathrm{CHO}$, but its physical properties cause certain difficulties with chewing and swallowing (6). We prepared a modified rice cake by mixing sweet potatoes in glutinous rice; the resulting product had intermediate physical properties between liquids and solids, that is, the SPRC could be easily chewed and swallowed. We demonstrated that SPRC could serve as a CHO supply source during exercise and suppressed hunger sensations and tended to suppress thirsty during $60 \mathrm{~min}$ of exercise at $80 \% \mathrm{VO}_{2 \max }$.

Endurance athletes, such as cyclists or triathletes, often consume $\mathrm{CHO}$ in a solid form because it is difficult to consume the necessary quantity of CHOs during exercise from only liquids. $\mathrm{CHO}$ intake has been shown to delay the onset of fatigue and improve endurance capacity (11-13). Current recommendations (1, 14-16) suggest that athletes consume large amounts of $\mathrm{CHO}$ before and during prolonged exercise to optimize performance. For example, the recommended CHO intake is more than 30 to $60 \mathrm{~g} / \mathrm{h}$. In the present study, the hourly intakes of $\mathrm{CHO}$ and water were 37 and $262 \mathrm{~g}$ in the SPRC group, respectively. When $\mathrm{CHOs}$ were consumed entirely as liquids, the concentration of the $\mathrm{CHO}$ solution was $14 \%$. This high concentration of $\mathrm{CHO}$ solution is far above the composition of common sports drinks (4-7\%). Therefore, a practical sporting supplementation of $\mathrm{CHO}$ was a combination of solids (e.g., energy bar), liquids (e.g., sports drink), and intermediate forms (e.g., gels).

Athletes can easily consume a larger amount of $\mathrm{CHO}$ from glutinous rice cake than from boiled rice because glutinous rice cake contains $40 \%$ more $\mathrm{CHO}$ than boiled rice (4). However, glutinous rice cake is not used as food for CHO supplementation during endurance because of its certain difficulties in mastication and swallowing; moreover, glutinous rice cake sometimes causes foodchoking accidents in Japan $(17,18)$. Several studies have attempted to modify the physical properties of glutinous rice cake by substituting glutinous rice with another CHO, such as resistant starch (19) or dietary fiber (20). A modified rice cake product was reported to be consumed with less mastication effort than a glutinous rice cake $(8)$.

In the present study, sweet potato was added to the glutinous rice cake. Sweet potato [Ipomoea batatas (L.), Lam] is one of the most important food crops worldwide, and China accounts for more than $85 \%$ of the world's production. The possibility of using sweet potato flour for making pasta/spaghetti products has been explored by many researchers (21-24). Sweet potato starch is reported to have free swelling and non-congealing properties and exhibits a type A-Brabender amylograph pat- tern (25-29).

SPRC was demonstrated to require less effort for mastication and swallowing compared to the glutinous rice cake. The effort of mastication and swallowing is alleviated when a smaller sized bolus is ingested because the size of food appears to influence the rapidity of this process (30).

The respiratory quotient, blood glucose, and lactate levels, which are indices of glucose metabolism, did not differ between the $\mathrm{CHO}$ gel and SPRC groups during $60 \mathrm{~min}$ of exercise at an intensity of $80 \% \mathrm{VO}_{2 \text { max }}$. Several studies have elucidated that blood glucose, insulin levels, and exercise performance do not differ between solid and liquid forms of $\mathrm{CHO}$. The ingestion of solid $\mathrm{CHO}$ and gels has been shown to increase exercise performance compared to water (31). Solid bananas are as effective as slurried bananas in maintaining plasma glucose and enhancing performance in endurance exercises (32). Pfeiffer et al. demonstrated that $\mathrm{CHO}$ ingested in the form of a solid bar or liquid drink resulted in similar mean and peak exogenous $\mathrm{CHO}$ oxidation rates (33).

Repeated solid CHO feedings maintain blood glucose levels, reduce muscle glycogen depletion during prolonged exercise, and enhance sprint performance at the end of exercise $(11,34)$. Therefore it is important to alleviate the mastication (chewing) and swallowing difficulties encountered when consuming solid CHO.

Solid food generally contains less water because it has high-density nutrients including CHO. In the present study, subjects who ingested SPRC consumed approximately $60 \mathrm{~g}$ less water than subjects who ingested $\mathrm{CHO}$ gel during $60 \mathrm{~min}$ of exercise. Furthermore, the thirst rating tended to be lower in the SPRC group during 60 min of exercise $(p<0.10)$ compared to the CHO gel group. Thirst increases linearly as plasma osmolality increases. Thus, osmotically unbalanced fluid or gel would promote the sensation of thirst because it would result in a change of plasma osmolality (35). Humans drink before deficits in body fluid develop, perhaps in response to subtle oropharyngeal cues, and thus provide evidence for anticipatory thirst (36).

Visual analog scale parameters demonstrated that indices concerning fullness and hunger were alleviated to a greater degree by the ingestion of SPRC compared to CHO gel. The meal consistency is an important physical food characteristic that influences both the gastric emptying rate and satiety sensation (37). This observation of perceived stomach fullness coincided with previous study (33).

There were large differences in chemical forms of carbohydrates of two test diets. SPRC contains not only dietary fiber as well as amylopectin, sucrose derived from sweet potato, glutinous rice powder, and sucrose, respectively. CHO gel contains liquid dextrin and fructose-glucose syrup and no dietary fibers. The molecular sizes of mono-/di-/poly-saccharides in SPRC were larger compared to $\mathrm{CHO}$ gel in which mono-/di-/poly-saccharides were partially or largely hydrolyzed. Therefore the rate of digestion and absorption in SPRC considered to be slower than that in CHO gel. 
Previous studiy revealed that feeding of the wholemeal breads containing dietary fibers caused significantly slower glucose appearance rate and lower blood insulin level than refined bread, even though there were no significant changes in blood glucose level (38). Another study also reported that high glycemic meal caused faster glucose appearance rate and higher blood insulin level than lower glycemic index meal, though there observed no consecutively high blood glucose level (39). Interestingly, both studies reported that high glycemic samples cause high blood glucose temporary but subsequently causes lower blood glucose. Therefore there are no contradictions in our study that average glucose level was slightly lower in $\mathrm{CHO}$ gel than in SPRC and there were no significant differences in blood glucose $(p=0.24$ at $60 \mathrm{~min}$ ).

Larger molecular sizes in SPRC could led two beneficial effects. Firstly, slower digestion and absorption derived from larger molecular size and dietary fiber maintained subjects's fullness and retarded their hunger. Secondary, smaller molecular size of $\mathrm{CHO}$ gel correlate to higher osmolarity compared to SPRC. In addition to the difference of molecular size, liquid form of $\mathrm{CHO}$ gel lead to higher osmolarity compared to solid form of SPRC. Therefore the osmosensor in oropharyngeal signals monitors the low osmolarity of SPRC and suppress the feeling of thirsty (40).

Some limitations exist in this study. First, there were no observed differences in exercise performance. The exercise time used in the present study was relatively short (60 min) for investigating the effect of CHO supply. However, this period was inevitable because our interest in the present study was to investigate whether a modified rice cake could be masticated and swallowed during high-intensity exercise. Much longer exercise duration at high exercise intensity would be appropriate to investigate the effect of supplied $\mathrm{CHO}$, although it was hard for our subjects to exercise for more than $2 \mathrm{~h}$ at the exercise intensity of $80 \% \mathrm{VO}_{2 \max }$. Further studies should be conducted using the research design by Talanian and Spriet (41), which consists of repeated sessions of $80 \%$, $50 \%$, and $30 \% \mathrm{VO}_{2 \max }$. Second, modifying the rice cakes alleviated the effort of mastication and swallowing, but muscle EMG data demonstrated that the effort to masticate and swallow SPRC was larger than that for $\mathrm{CHO}$ gel. Therefore, further improvements must be made to prepare food products that can be easily masticated and swallowed.

In conclusion, the effort required for mastication and swallowing was alleviated by adding sweet potato to the glutinous rice cake. Time trial performance after consuming this modified rice cake was equivalent to that after consuming $\mathrm{CHO}$ gel. While there was no positive effect on time trial performance after 60 min of exercise, the feelings of thirst and hunger were alleviated by the SPRC. This modified rice cake could supply CHO during cycling exercise at an intensity of $80 \% \mathrm{VO}_{2 \max }$.

\section{Author contributions}

K.I. and Y.A. conceived and designed the study.
K.I., N.A., and Y.A. performed the data collection. K.I. analyzed the data. K.I. and H.T. drafted the manuscript. All authors edited and approved the final draft of the manuscript.

\section{Disclosure of state of COI}

The authors declare no conflict of interest. The founding sponsors had no role in the design of the study; in the collection, analyses, or interpretation of data; in the writing of the manuscript; and in the decision to publish the results.

\section{Funding}

This work was supported by the Sugiyama Sangyo Kagaku Institute.

\section{Acknowledgments}

We are grateful to all the volunteers for participating in this study. We also thank Masayuki Shibata, Mitsutaka Maeda, and Michimasa Nakai for their advice on the physical properties of SPRC for elite cyclists. Finally, we thank Miho Ishihara for her advice and expertise in English writing. This project was supported by the Ryukoku University Department of Agriculture.

\section{Supporting information}

Supplemental online material is available on J-STAGE.

\section{REFERENCES}

1) Stellingwerff T, Cox GR. 2014. Systematic review: carbohydrate supplementation on exercise performance or capacity of varying durations. Appl Physiol Nutr Metab 39: 998-1011.

2) Jeukendrup A. 2014. A step towards personalized sports nutrition: carbohydrate intake during exercise. Sport Med 44: 25-33.

3) de Oliveira EP, Burini RC. 2014. Carbohydratedependent, exercise-induced gastrointestinal distress. Nutrients 6: 4191-4199.

4) Office for Resources PDS and TPB. 2015. Standard Tables of Food Composition in Japan-2015-, Seventh Revised Version.

5) Atkinson FS, Foster-Powell K, Brand-Miller JC. 2008. International tables of glycemic index and glycemic load values: 2008. Diabetes Care 31: 2281-2283.

6) Iguchi H, Magara J, Nakamura Y, Tsujimura T, Ito K, Inoue M. 2015. Changes in jaw muscle activity and the physical properties of foods with different textures during chewing behaviors. Physiol Behav 152: 217-224.

7) Katayama K, Tamiya S, Sakai T, Kai Y, Ohara-Takada A, Kuranouchi T, Yoshinaga M. 2015. Inheritance of low pasting temperature in sweetpotato starch and the dosage effect of wild-type alleles. Breed Sci 65: 352-356.

8) Kohyama K, Sawada H, Nonaka M, Kobori C, Hayakawa F, Sasaki T. 2007. Textural evaluation of rice cake by chewing and swallowing measurements on human subjects. Biosci Biotechnol Biochem 71: 358-365.

9) Shirreffs SM, Watson P, Maughan RJ. 2007. Milk as an effective post-exercise rehydration drink. Br J Nutr 98(1):173-180.

10) Frayn KN. 1983. Calculation of substrate oxidation rates in vivo from gaseous exchange. J Appl Physiol 55: 628-634. 
11) Hargreaves M, Costill DL, Coggan A, Fink WJ, Nishibata I. 1984. Effect of carbohydrate feedings on muscle glycogen utilization and exercise performance. Med Sci Sports Exerc 16: 219-222.

12) Coyle EF, Hagberg JM, Hurley BF, Martin WH, Ehsani AA, Holloszy JO. 1983. Carbohydrate feeding during prolonged strenuous exercise can delay fatigue. J Appl Physiol 55: 230-235.

13) Murray R, Seifert JG, Eddy DE, Paul GL, Halaby GA. 1989. Carbohydrate feeding and exercise: effect of beverage carbohydrate content. Eur J Appl Physiol Occup Physiol 59: 152-158.

14) 2011. IOC consensus statement on sports nutrition 2010. J Sports Sci 29 Suppl 1: S3-S4.

15) Jeukendrup A, Mensink M, Saris WH, Wagenmakers J. 1997. Exogenous glucose oxidation during exercise in endurance-trained and untrained subjects. J Appl Physiol 82: 835-840.

16) Jeukendrup A. 2013. The new carbohydrate intake recommendations. Nestle Nutrition Institute Workshop Series, p 63-71.

17) Inoue K, Fujita Y, Okazaki Y, Noso Y, Takeshita H. 2016. The current state of accidents involving choking on mochi (glutinous rice cakes) during New Year's in Japan and measures to prevent them: A study focusing on the elderly. J Forensic Leg Med 42: 63-64.

18) Kiyohara K, Sakai T, Nishiyama C, Nishiuchi T, Hayashi Y, Iwami T, Kitaura T. 2018. Epidemiology of out-of-hospital cardiac arrest due to suffocation focusing on suffocation due to Japanese rice cake: A population-based observational study from the Utstein Osaka Project. J Epidemiol 28(2): 67-74.

19) Tsatsaragkou K, Papantoniou M, Mandala I. 2015. Rheological, physical, and sensory attributes of glutenfree rice cakes containing resistant starch. J Food Sci 80: E341-348.

20) Yoon NR, Yoon S, Lee S-M. 2016. Rice cakes containing dietary fiber supplemented with or without Artemisia annua and Gynura procumbens Merr. alleviated the risk factors of metabolic syndrome. Clin Nutr Res 5: 79-88.

21) Collado LS, Corke H. 1997. Properties of starch noodles as affected by sweetpotato genotype. Cereal Chem J 74: 182-187.

22) Limroongreungrat K, Huang YW. 2007. Pasta products made from sweetpotato fortified with soy protein. Food Sci Technol 40: 200-206.

23) Krishnan JG, Menon R, Padmaja G, Sajeev MS, Moorthy SN. 2012. Evaluation of nutritional and physicomechanical characteristics of dietary fiber-enriched sweet potato pasta. Eur Food Res Technol 234: 467-476.

24) Gopalakrishnan J, Menon R, Padmaja G, Sajeev MS, Moorthy SN. 2011. Nutritional and functional characteristics of protein-fortified pasta from sweet potato. Food Nutr Sci 2: 944-955.

25) Schoch TJ, Maywald EC. 1968. Preparation and properties of various legume starches. Cereal Chem 45: 564-573.

26) Tian SJ, Rickard JE, Blanshard JM. 1991. Physicochemi- cal properties of sweet potato starch. J Sci Food Agric 57: 459-491.

27) Balch RT, Paine HS. 1931. Production of starch from sweet potatoes. Ind Eng Chem 23: 1205-1213.

28) Haidar A, Elleri D, Allen JM, Harris J, Kumareswaran K, Nodale M, Acerini CL, Wilinska ME, Jackson N, Umpleby AM, Evans ML, Dunger DB, Hovorka R. 2012. Validity of triple- and dual-tracer techniques to estimate glucose appearance. Am J Physiol Endocrinol Metab 302: E1493-1501.

29) Thurber FH. 1933. Chemical and physical properties of sweet potato starch. Ind Eng Chem 25: 565-568.

30) Holt S, Reid J, Taylor T V, Tothill P, Heading RC. 1982. Gastric emptying of solids in man. Gut 23: 292-296.

31) Campbell C, Prince D, Braun M, Applegate E, Casazza GA. 2008. Carbohydrate-supplement form and exercise performance. Int J Sport Nutr Exerc Metab 18: 179-190.

32) Murdoch SD, Bazzarre TL, Snider IP, Goldfarb AH. 1993. Differences in the effects of carbohydrate food form on endurance performance to exhaustion. Int J Sport Nutr 3: 41-54.

33) Pfeiffer B, Stellingwerff T, Zaltas E, Jeukendrup AE. 2010. Oxidation of solid versus liquid CHO sources during exercise. Med Sci Sports Exerc 42: 2030-2037.

34) Fielding RA, Costill DL, Fink WJ, King DS, Hargreaves M, Kovaleski JE. 1985. Effect of carbohydrate feeding frequencies and dosage on muscle glycogen use during exercise. Med Sci Sports Exerc 17: 472-476.

35) Hughes F, Mythen M, Montgomery H. 2018. The sensitivity of the human thirst response to changes in plasma osmolality: a systematic review. Perioper Med (Lond) 7: 1 .

36) Phillips PA, Rolls BJ, Ledingham JG, Morton JJ. 1984. Body fluid changes, thirst and drinking in man during free access to water. Physiol Behav 33: 357-363.

37) Santangelo A, Peracchi M, Conte D, Fraquelli M, Porrini M. 1998. Physical state of meal affects gastric emptying, cholecystokinin release and satiety. Br J Nutr $\mathbf{8 0}(6)$ : 521-527.

38) Östman JR, Müllner E, Eriksson J, Kristinsson H, Gustafsson J, Witthöft C, Moazzami AA. 2019. Glucose appearance rate rather than the blood glucose concentrations explains differences in postprandial insulin responses between wholemeal rye and refined wheat breadsresults from a cross-over meal study. Mol Nutr Food Res 63(7): e1800959.

39) Febbraio MA, Keenan J, Angus DJ, Campbell SE, Garnham AP. 2000. Preexercise carbohydrate ingestion, glucose kinetics, and muscle glycogen use: effect of the glycemic index. J Appl Physiol 38(5): 1845-1851.

40) Zimmerman CA, Huey L, Ahn JS, Beutler LR, Lek Tan C, Kosar S, Knight ZA. 2012. A gut-to-brain signal of fluid osmolarity controls thirst satiation. Nature $\mathbf{5 6 8}$ : 98-102.

41) Talanian JL, Spriet LL. 2016. Low and moderate doses of caffeine late in exercise improve performance in trained cyclists. Appl Physiol Nutr Metab 41: 850-855. 